\title{
El plan económico, ¿es bueno o malo?
}

Con seguridad, en lo que va del año, la discusión más prolongada e importante que ha tenido lugar entre los círculos gubernamentales y políticos salvadoreños, con la participación de algunas expresiones organizadas de la sociedad civil y la cobertura amplia de los medios masivos de difusión, ha sido la que giró alrededor de ciertas medidas económicas propuestas por el gobierno de Armando Calderón Sol. Ni las denuncias de corrupción en la administración pública o el sostenimiento de la impunidad, ni el creciente sentimiento de inseguridar que existe entre la población o las protestas - violentas y repetidas - de los desmovilizados de la Fuerza Armada, ni la infatigable búsqueda de los niños desaparecidos durante la guerra o la elección del Procurador para 1a Defensa de los Derechos Humanos, ni el incumplimiento de los acuerdos de paz...

$\mathrm{Ni}$ estos ni otros acontecimientos tuvieron, en la práctica, la fuerza suficiente para desplazar del primer plano de la polémica nacional las expectativas y los temores que las medidas económicas despertaron en amplios sectores sociales. Para algunos, estas medidas son un "paquetazo", pero para otros son "un plan económico". Para los primeros, las medidas son un estímulo para una "lucha frontal", para los otros, una necesidad impostergable.

Desde finales de diciembre $y$, sobre todo, recién comenzado el mes de enero - tras la designación de Manuel Enrique Hinds como titular de la cartera de hacienda - se empezaron a conocer algunos elementos de la nueva política económica.
El primer mandatario anunció a la cúpula de la empresa privada la versión inicial de las medidas, no obstante los reiterados y no muy lejanos pronunciamientos oficiales negando su existencia. El mismo presidente Calderón había negado hacía poco tiempo la existencia de algunas de esas medidas.

Casi inmediatamente surgieron las opiniones, la mayoría de ellas en contra de las medidas presentadas; solamente los voceros del gobierno se pronunciaron a favor de ellas. Un mes después, el gobierno modificó algunos aspectos de la propuesta inicial. Así, el 2 de febrero, el presidente Calderón anunció a la nación la llamada "Plataforma económica para el desarrollo social", cuyo objetivo es "transformar a El Salvador en un país de oportunidades, con equidad". No obstante las modificaciones, las medidas siguieron provocando reacciones en contra de muchos sectores sociales.

Ahora bien, el debate de las medidas no ha sido completo. Pese a su intensidad y extensión, los derechos humanos han estado ausentes. Cualquier iniciativa que se tome en materia económica, sobre todo en países como el nuestro, debe hacerse considerando su efecto en las necesidades básicas de la población, a partir del acceso que ésta tenga a sus satisfactores, los cuales se encuentran contemplados como derechos en diferentes instrumentos internacionales, tanto de Naciones Unidas como del sistema interamericano, y nacionales. La perspectiva de los derechos humanos es importante para determinar si las políticas económicas favorecen o no el bienestar de la población, para 
señalar sus bondades e inconvenientes, para descubrir sus verdades y falacias.

La vigencia de los derechos económicos sociales y culturales exige una acción positiva por parte del Estado, a diferencia de los derechos civiles y políticos que —en su mayoría- requieren sólo del reconocimiento y el respeto de las instituciones y los agentes estatales. Esto significa que para que realmente los derechos económicos y sociales sean efectivos es necesario que existan y se apliquen programas gubernamentales que apunten a su plena vigencia. Así, por ejemplo, el Estado debe impulsar planes específicos para solucionar el problema de la vivienda, pero no debe desarrollar políticas represivas contra aquellos que en la sociedad civil se organizan para exigir condiciones de vida dignas.

La acción positiva del Estado en el ámbito de los derechos económicos, sociales y culturales no debe ser interpretada como una primacía de éstos sobre los civiles y políticos. La Declaración sobre el Derecho al Desarrollo, aprobada en 1986, mediante la resolución $41 / 128$ de la asamblea general de Naciones Unidas, establece que todos los derechos y todas las libertades fundamentales "son indivisibles $e$ interdependientes; debe darse igual atención y urgente consideración a la aplicación, promoción y protección de los derechos civiles, políticos, económicos, sociales y culturales".

Desde antes, en el preámbulo de cada uno de los pactos internacionales de Naciones Unidas, se reconoce que, "con arreglo a la Declaración Universal de Derechos Humanos, no puede realizarse el ideal del ser humano libre, liberado del temor y de la miseria, a menos que se creen condiciones que permitan a cada persona gozar de sus derechos económicos, sociales y culturales, tanto como de sus derechos civiles y políticos". No es posible que en una situación de injusticia estructural se pueda hablar de un clima de respeto real al grupo de derechos conocido como de la "primera generación". Pero también, para que un gobierno oriente sus programas económicos hacia el desarrollo y beneficio de la sociedad entera, sin exclusiones de ningún tipo, es fundamental que la población tenga capacidad para exigirlo, participando activamente en el control de las instituciones estatales. Por lo tanto, es necesario que la población tenga asegurado el respeto efectivo de sus derechos civiles y políticos.

Así, pues, si los "planes" o "programas" económicos y las medidas que se adoptan para su aplicación no están dirigidos a la satisfacción de las necesidades básicas de todas las personas; si por el contrario, en la búsqueda de un supuesto beneficio a largo plazo de la población, sus condiciones de vida se deterioran aún más y si, por lógica, no cuentan con el apoyo real de la población, resulta evidente que su implementación requerirá de una buena dosis de autoritarismo el cual, irremediablemente, derivará en detrimento progresivo del llamado "núcleo duro" de los derechos humanos, es decir, del derecho a la vida, a la libertad, a la seguridad y a la integridad física. Si este es el rumbo de las medidas económicas que el gobierno pretende impulsar en la actualidad, como parte de la aplicación y profundización del ajuste estructural, no podemos aceptar - pensando desde el lado de las mayorías- que éstas sean buenas para el país. Otras experiencias y la nuestra, así como algunos estudios de Naciones Unidas, acrecientan este temor inicial.

Mucho se ha hablado de dar un "rostro humano" a los programas de ajuste estructural al ver los efectos negativos que causan en la población. Algo se ha hecho, por ejemplo, al crear las llamadas "redes de seguridad social". Sin embargo, estas iniciativas no han arrojado resultados alentadores en cuanto a disminuir el costo del sacrificio que dichos programas implican para los pueblos. Ya en junio de 1990, el Secretario General de Naciones Unidas sostuvo que "las políticas de ajuste estructural han empeorado la situación de los pobres. Los sueldos reales han bajado, el acceso a la sanidad y la educación se ha visto reducido, y en algunos países el declive de la mortalidad infantil ha sido más lento o incluso se ha paralizado por completo" (Consejo Económico y Social, Subcomisión de Prevención de Discriminaciones y Protección a las Minorías, Comisión de Derechos Humanos, "Realización de los derechos económicos, sociales y culturales", E/ CN.4/Sub.2/1992/16, 3 de julio de 1992, 60).

A lo anterior, el informe agrega lo siguiente: 
"En muchos otros informes de las Naciones Unidas se llega a conclusiones análogas en relación con las consecuencias humanas del ajuste, incluidos algunos documentos del Departamento de Asuntos Económicos y Sociales Internacionales, la Comisión Económica para América Latina y el Caribe (CEPAL) y de los propios órganos de derechos humanos" (ibid., 61). Sin embargo, con la retórica propia de los defensores de estas políticas, se proclaman sus "bondades" y las agencias internacionales de financiamiento se atreven a sostener que su aplicación es imprescindible para la realización de los derechos económicos sociales y culturales. Además, según el Banco Mundial, "no hay otras opciones a la forma de ajuste estructural que propugnan" (ibid., 48) y, para que ésta sea aceptada, se condiciona la entrega de la asistencia a los países necesitados.

En el informe antes mencionado se indica que la "apertura de una economía nacional puede considerarse necesaria para que prosperen determinados procesos económicos y es inevitable $-\mathrm{y}$, de hecho, deseable - cierto grado de apertura" (ibid., 45). No obstante, agrega, "el proceso de liberalización también tiende a crear tendencias correlacionadas, como una reducción de la capacidad de fiscalización por parte de los estados, una disminución relativa de la independencia nacional y la sujeción de ciertos procesos a los factores condicionantes del mercado mundial. Desde luego, cada una de estas tendencias puede reducir la capacidad del gobierno nacional o local de crear las condiciones necesarias para la realización de los derechos económicos, sociales y culturales" (ibid.).

Algunos lo considerarán innecesario, sin embargo, nunca es inoportuno recordar las necesidades básicas del ser humano y los satisfactores mínimos requeridos para cubrirlas, sobre todo cuando la realidad cotidiana niega a muchos el disfrute de una vida digna y cuando —cada vez más- para los encargados de impulsar las políticas destinadas a tal fin, es un tema que se encuentra en el olvido u opacado por el brillo de sus ganacias y beneficios personales. Ello, para pre-

cisar lo que el relator especial de Naciones Unidas considera que está siendo afectado de manera negativa por los programas de ajuste estructural.

En el Pacto Internacional de Derechos Económicos, Sociales y Culturales, tenemos una buena guía. En él, los estados reconocen el derecho de todas y todos a "ganarse la vida mediante un trabajo libremente escogido o aceptado", según el artículo sexto; para tal fin, los estados adoptarán las medidas necesarias entre las cuales se encuentran las siguientes: la orientación y formación técnica y profesional, la preparación de programas, normas y técnicas encaminadas a conseguir un desartollo económico, social y cultural y la ocupación plena y productiva, en condiciones que garanticen las libertades políticas y económicas fundamentales de la persona. Siempre en relación al mismo punto, el siguiente artículo se refiere al reconocimiento del derecho de todas y todos a gozar "de condiciones de trabajo equitativas y satisfactorias" para asegurar, primero, una remuneración que proporcione a las personas, pero de modo especial a las mujeres, un "salario equitativo e igual por trabajo de igual valor, sin distinciones de ninguna especie" y para garantizarles condiciones dignas de existencia en lo individual y familiar.

En el artículo octavo se incluye el compromiso de los estados para garantizar los siguientes derechos: a la huelga y a fundar sindicatos, así como a incorporarse al sindicato de su elección "para promover y proteger sus intereses económicos y 
sociales". Se acepta asegurar que los sindicatos funcionen "sin obstáculos y sin otras limitaciones que las que prescribe la ley" y la capacidad para formar federaciones o confederaciones nacionales y que éstas, a su vez, puedan constituir organizaciones internacionales o pertenecer a ellas". Finalmente, en relación al mismo tema, por el artículo noveno, los estados reconocen el "derecho de toda persona a la seguridad social, incluso al seguro social".

A continuación, en el artículo décimo, el pacto afirma el reconocimiento de la familia como "elemento natural y fundamental de la sociedad". A ella, dice el texto, se debe conceder "la más amplia protección y asistencia posibles, especialmente para su constitución". También debe brindarse "especial atención a las madres durante un período de tiempo razonable antes y después del parto". Cuando éstas trabajen asalariadamente, se les debe "conceder licencia con remuneración o con prestaciones adecuadas de seguridad social". Finalmente, se hace referencia a la población infantil y adolescente. En beneficio de ésta, los estados se comprometen a la adopción de medidas especiales para protegerla y asistirla sin discriminación alguna, enfatizando las medidas para impedir su explotación económica y social. Para ello se habla de sancionar su empleo "en trabajos nocivos para su moral y su salud, o en los cuales peligre su vida o se corra el riesgo de perjudicar su desarrollo normal", puntualizando que los "estados deben establecer también límites de edad por debajo de los cuales quede prohibido y sancionado por la ley el empleo a sueldo de mano de obra infantil".

El reconocimiento del derecho que tiene toda persona "a un nivel de vida adecuado para sí y su familia, incluso a alimentación, vestido y vivienda adecuados, y a una mejora continua de las condiciones de existencia", se encuentra en el artículo 11. En este artículo, a partir del reconocimiento del "derecho fundamental de toda persona a estar protegida contra el hambre", se plantea el compromiso de los estados para adoptar, por sí mismos y con la cooperación internacional, las medidas y los programas concretos a fin de mejorar la producción y conservación de alimentos, así como para asegurar su distribución equitativa.
En el artículo siguiente se reconoce el derecho de toda persona a la salud física y mental y a disfrutarla en su "nivel más alto posible", para lo cual los estados deben adoptar las siguientes medidas: reducir la mortinatalidad y la mortalidad infantil, garantizar el sano desarrollo de la población infantil, mejorar en todos sus aspectos el medio ambiente y la higiene en el trabajo, prevenir, tratar y luchar contra las enfermedades epidémicas, endémicas, profesionales y de otra índole $\mathrm{y}$, finalmente, asegurar a todas y todos asistencia y servicios médicos en caso de enfermedad.

Sobre la educación, los artículos 13 y 14 dan cuenta detallada de las obligaciones estatales determinadas en el pacto, las cuales deben "orientarse hacia el pleno desarrollo de la personalidad humana y del sentido de su dignidad", "fortalecer el respeto por los derechos humanos $y$ las libertades fundamentales", "capacitar a todas las personas para participar efectivamente en una sociedad libre", "favorecer la comprensión, la tolerancia, y la amistad entre las naciones y entre todos los grupos raciales, étnicos o religiosos" y "promover las actividades de las Naciones Unidas en pro del mantenimiento de la paz". En consecuencia, se han fijado los siguientes compromisos: procurar que la enseñanza primaria sea obligatoria, gratuita y asequible a todas y todos; lograr que la enseñanza secundaria -incluso la técnica y profesional- sea generalizada y accesible a todas y todos, "por cuantos medios sean apropiados, y en particular por la implantación progresiva de la enseñanza gratuita"; alcanzar una enseñanza superior accesible a todas y todos, en los mismos términos que la anterior; fomentar o intensificar, en lo posible, la educación fundamental para quienes "no hayan recibido o terminado el ciclo completo de educación primaria" y desarrollar el sistema escolar en todos los niveles de enseñanza, implantando un sistema adecuado de becas y mejorando constantemente las condiciones materiales del cuerpo docente.

Finalmente, el artículo 15 plantea el reconocimiento del derecho que tiene toda persona a participar en la vida cultural, a gozar de los beneficios del progreso científico y a beneficiarse "de la protección de los intereses morales y materiales 
que le correspondan por razón de las producciones científicas, literarias o artísticas de que sea autora". Además, se habla de adoptar, para la realización de lo anterior, las medidas necesarias "para la conservación, el desarrollo y la difusión de la ciencia y la cultura", así como de "respetar la indispensable libertad para la investigación científica y para la actividad creadora".

Antes de comentar los efectos de las medidas económicas que pretende impulsar el gobierno salvadoreño en la realización de los derechus económicos; sociales y culturales de la población, sobre todo en aquellos sectores que siempre han sido excluidos de su disfrute, cabe recordar algunos aspectos de otras experiencias latinoamericanas. No está de más tener en cuenta lo que otros ya vivieron y sufrieron, sobre todo cuando en El Salvador nos empeñamos en desdeñar las lecciones dolorosas del pasado reciente, marcado por la violencia política y militar, cuyo origen último se encuentra en la injusticia social, en la falta de espacios para la participación política y en la impunidad. Las experiencias de Chile, Bolivia y México son importantes desde la perspectiva del impacto negativo de estas políticas en los derechos humanos, mientras que la de Uruguay es interesante desde la perspectiva de la oposición ciudadana a la privatización.

Los resultados del llamado modelo chileno son los siguientes (Fernando Ignacio Leiva, "La apertura y los trabajadores: la otra cara del modelo chileno", boletín Alerta a la apertura). En 1969, el 28.5 por ciento de los hogares se encontraba por debajo de la línea de la pobreza; en 1979, el nivel subió hasta el 36 por ciento y en 1989, llegó al 41.2 por ciento hasta llegar, dos años después, a superar el 48 por ciento. En 1969, el 20 por ciento más pobre de los hogares que participaba en el 7.6 por ciento del consumo, redujo su participación al 5.2 por ciento en 1978 y al 4.4 por ciento en 1988 ; mientras que el 20 por ciento más rico de los hogares fue aumentando su participación en el consumo de la siguiente forma: en 1969, alcanzó el 44.5 por ciento, en 1978 llegó al 51 por ciento y en 1988 al 55 por ciento. En relación al empleo, los resultados se reflejan en el aumento de los desocupados: de 143 mil en 1972 se pasó a más de un millón en 1983. Según la tercera encuesta de empleo e ingreso del Programa de Economía del Trabajo, en 1991, los ingresos del 60 por ciento de los trabajadores de Santiago eran inferiores al salario mínimo necesario para satisfacer sus necesidades básicas y las de sus familias.

¿Quién ignora el desmantelamiento de la organización sindical chilena mediante la persecusión, la cárcel y la muerte de dirigentes y afiliados? Tras eso, el Código de Trabajo "impuso severas restricciones a la negociación colectiva y a la huelga. Le otorgó una mayor discrecionalidad a las empresas y eliminó la intervención sindical en temas tales como despidos, cambios organizacionales, movilidad entre puestos y labores, fijación de turnos de trabajo, restricciones para contratar trabajo temporario y recurrir a subcontratistas" (ibid., p. 4). Al llegar a la presidencia, Patricio Allwyn mantuvo los elementos centrales de la legislación laboral de Pincohet, pues consideró que si se regresaba a las relaciones laborales que existían antes de 1973, se pondría en peligro la competitividad de las exportaciones chilenas que, en los ochenta, se basó en una caída de los salarios reales del 20 por ciento y en el deterioro de las condiciones de trabajo, al punto de llegar a registrarse, por ejemplo, un considerable aumento de los accidentes de trabajo: de 91,749 en 1980 se pasó a 242,361 en 1990.

En Bolivia (Ontiveros Cabrera, "Neoliberalismo y respuesta popular en Bolivia", boletín Alerta a la apertura, marzo de 1993), la condición comunitaria y colectivista del país fue transformada al transferir las grandes decisiones económico sociales a pequeños grupos con grandes recursos. Desde 1985, cuando se adoptaron las medidas neoliberales, han sido despedidos más de 80 mil trabajadores. Sólo en Oruro, ciudad limítrofe con Chile, a partir de entonces 2,783 establecimientos económicos quebraron, según el censo de 1992. El 80 por ciento de los hogares vive por debajo de la línea de pobreza. El promedio de la esperanza de vida es de 53 años. El 54 por ciento de la población sufre desnutrición. Sólo el 34.29 por ciento tiene acceso a la electricidad y el 72 por ciento de la población no cuenta con servicios básicos. 
Para la organización de los trabajadores y otros sectores sociales bolivianos, las consecuencias de la experiencia han sido duras y aleccionadoras: "el despido de trabajadores afectó profundamente la capacidad de convocatoria y movilización de la Central Obrera Boliviana. En muchos casos, el movimiento popular acosado por el hambre, aceptó resignado los cambios con la esperanza de que su situación económica mejoraría. Vana expectativa porque a siete años de la aplicación de los ajustes estructurales, la pobreza se ha enseñoreado en grandes sectores de la clase media, lo que últimamente está provocando un lento y paulatino fortalecimiento de las organizaciones sindicales" (ibid., p. 2). Así, "desde 1985, Bolivia sufre constantes oleadas de conflictos sociales. Los gobiernos han apelado a tres decretos de estado de sitio para frenar avalanchas de descontento social. Durante siete años los mineros han resistido contra la privatización de las minas, las regiones deprimidas luchan contra el presupuesto restrictivo, los maestros se movilizan por mejores sueldos, las universidades pelean por recursos para subsistir y hubo momentos en que incluso la policía se amotinó demandando mejores sueldos" (ibid., p. 3).

En México, Cuahutémoc Cárdenas, ante la reciente crisis económica, declaró, "nuestro país está viviendo una crisis prevista por todos y anunciada desde hace varios años por quienes nos movemos en el campo democrático, por académicos, investigadores, por empresarios y financieros de dentro y de fuera. Llegó lo único que podía traer la corrupción, las imposiciones políticas, el entreguismo, la ineptitud; una crisis que vulnera la soberanía y pone en riesgo la seguridad nacional y que golpea severamente los niveles de vida y las capacidades creativas y productivas de trabajadores y productores" ("Por un gobierno de salvación nacional", La Jornada, 7 de enero de 1995, p. 11). "En México" —continúa el dirigente político-, "nadie que razone con objetividad podrá dejar de reconocer que el modelo neoliberal que gobernantes y financieros entreguistas nos han impuesto desde 1982, siguiendo linamientos del Fondo Monetario Internacional y del Banco Mundial, provoca crisis recurrentes que se mani- fiestan, como ahora, en devaluación de nuestra moneda, en inflación, en estancamiento económico, etc., y que este modelo en el terreno social, más allá de proponerse la concentración del ingreso en unos cuantos, no se plantea aumentar el empleo, ni elevar salarios y niveles de vida generales, ni ampliar los servicios para el bienestar, ni nada que tenga que ver con el mejoramiento de la vida" (ibid.). ¿Que más agregar?

Ante estas tres realidades, la experiencia del Uruguay se plantea como un ejemplo para América Latina y, en especial, para nuestro país. Tras haber sido aprobada por el parlamento -en diciembre de 1991 - una ley de empresas públicas, mediante la cual se autorizaba la privatización de empresas estatales, el 13 de diciembre de 1992, un plebiscito se opuso a esa política, obligando a derogar los artículos claves de la mencionada ley. Con la Constitución de la República en la mano, sectores políticos de la oposición y la Central Obrera Uruguaya conformaron la Comisión Nacional pro Referéndum y Defensa del Patrimonio Nacional, a la que se integraron luego sectores de todos los partidos políticos del país. Entre los artículos derogados, al que más importancia se dio fue al de la empresa telefónica, que representaba una fuente de ingresos muy importante para el país — sus aportes anuales superan los 90 millones de dólares y tiene el mayor índice de instalaciones por habitante en América Latina. Así, la empresa es de los uruguayos en la actualidad (Pablo Díaz, "Uruguay dijo no a las privatizaciones", en Boletín Alerta a la apertura, mayo de 1993, p. 6).

Volviendo a El Salvador y ante la política económica gubernamental, conviene considerar algunos de los señalamientos del estudio de $\mathrm{Na}$ ciones Unidas, citado arriba, en concreto, la repercusión del proceso de ajuste sobre la soberanía nacional, la participación popular en su elaboración y la manera de someterlo al examen de la población antes de aplicarlo, la integración de criterios de derechos humanos en toda ecuación destinada a medir el éxito del plan, la exploración de alternativas viables al proceso de ajuste, las medidas concretas para proteger a los grupos sociales de las consecuencias negativas del ajuste, 
ampliando las medidas de protección actuales así como las redes de seguridad social, los efectos de la liberalización de la economía y el libre comercio sobre los derechos humanos, los mecanismos para asegurar que la retórica sobre la protección de los pobres y la utilización de las redes de seguridad social, por ejemplo, se materialicen en forma efectiva.

De no ser así, los pocos y débiles logros que en materia de derechos civiles y políticos se han obtenido tras el fin de la guerra en El Salvador, se pueden esfumar. Recordemos que la democracia debe medirse tanto en su cantidad como en su calidad, lo cual exige niveles realmente aceptables de participación política y de bienestar social. Asimismo, recordemos, superando las posturas retóricas y demagógicas, que no basta con generar oportunidades si la mayoría no está en condiciones para aprovecharlas $\mathrm{y}$, por eso, siempre terminan beneficiándose los mismos.

IDHUCA 